\title{
Scaling of Hunter Gatherer Camp Size and Human Sociality
}

\author{
José Lobo $^{1 *}$, Todd Whitelaw ${ }^{2}$, Luís M. A. Bettencourt ${ }^{3,7}$, Polly Wiessner ${ }^{4}$ \\ Michael E. Smith ${ }^{5}$, Scott Ortman ${ }^{6,7}$
}

May 26, 2019

\begin{abstract}
One of the most commonly-observed properties of human settlements, both past and present, is the tendency for larger settlements to display higher population densities. Work in urban science and archaeology suggests this densification pattern reflects an emergent spatial equilibrium where individuals balance movement costs with social interaction benefits, leading to increases in aggregate productivity and social interdependence. In this context, it is perhaps not surprising that the more temporary camps created by mobile hunters and gatherers exhibit a tendency to become less dense with their population size. Here we examine why this difference occurs and consider conditions under which hunter-gatherer groups may transition to sedentism and densification. We investigate the relationship between population and area in mobile huntergatherer camps using a dataset, representing a large cross-cultural sample, derived from the ethnographic literature. We present a model based on the interplay between social interactions and scalar stress for the relationship between camp area and group size that describes the observed patterns among mobile hunter-gatherers. The model highlights the tradeoffs between the costs and benefits of proximity and interaction that are common to all human aggregations and specifies the constraints that must be overcome for economies of scale and cooperation to emerge.
\end{abstract}

1. School of Sustainability, Arizona State University, Tempe, Arizona, USA. Email: jose.lobo@asu.edu

2. Institute of Archaeology, University College London, London, UK. Email: t.whitelaw@ucl.ac.uk

3. Mansueto Institute for Urban Innovation, Department of Ecology and Evolution, Department of Sociology, University of Chicago, Chicago, Illinois, USA.

Email: bettencourt@uchicago.edu

4. School of Human Evolution and Social Change, Arizona State University, Tempe, Arizona, USA. Email: pwiessne@asu.edu.

5. School of Human Evolution and Social Change, Arizona State University, Tempe, Arizona, USA. Email: michael.e.smith2@asu.edu.

6. Department of Archaeology, University of Colorado Boulder, Boulder, Colorado, USA. Email: scott.ortman@colorado.edu

7. Santa Fe Institute, Santa Fe NM 87501, USA.

*: Corresponding author. 


\section{Introduction}

A defining characteristic of Homo sapiens is ultra-sociality, which involves interacting and cooperating with individuals far beyond the immediate family group. One of the most important physical manifestations of this behavior is the concentration of people in space and time. Growth in the population size of the largest communities in settlement systems is interpreted by many scholars as the result of the overall net advantages of social agglomeration over dispersion, whenever the former is feasible. Indeed, the outstanding spatial feature of contemporary urban areas is their high population densities, which are much greater than those of premodern settlements (Bloom, Canning, and Fink 2008; Lees 2015). Urban economists and economic geographers have long attempted to explain the origin and maintenance of highdensity settlements as resulting from the net benefits of socioeconomic interactions facilitated by close proximity (Duranton and Puga 2004; Fujita, Krugman, and Venables 1999; Henderson 1988). Recent observations in sociology, archaeology and anthropology suggest that these advantages are quite general and do not require formal markets, modern administrative or political structures, wage labor, or industrialization to be realized (Ortman and Coffey 2017; Smith 2019; Ortman et al. 2016). These studies have shown that permanent settlements typically densify at consistent rates as their populations grow, in an open-ended way, in a wide range of societies, past and present.

In contrast, several studies have found that the temporary camps created by mobile hunters and gatherers (H/Gs) generally become less dense as the number of people gathered together increases (Wiessner 1974; Whitelaw 1991; Hamilton, Buchanan, and Walker 2018; Fletcher 1990). This strikingly different pattern raises several important questions regarding the cultural evolution of human spatial behavior, the conditions that enable a transition to sedentism, 
and the differences in human social life implied by the densification vs. de-densification regimes. In this paper we develop a framework for incorporating $\mathrm{H} / \mathrm{Gs}$ into the continuum of human spatial behavior, from temporary camps to permanent settlements, and consider the conditions that must be met for the $\mathrm{H} / \mathrm{G}$ scaling pattern to transition to the permanent settlement scaling pattern.

A wide array of hunting and gathering lifestyles has provided extraordinarily successful adaptations, deeply-rooted in our evolutionary history, which enabled humanity to spread across the globe (Shennan 2002; Henrich 2015; Wilson 2002; Cavalli-Sforza, Menozzi, and Piazza 1994; Bowles and Gintis 2011). This way of life is also remarkably stable and sustainable, exhibiting slow rates of social, environmental, and technological change in comparison with more settled and denser societies (Powell, Shennan, and Thomas 2009; Perreault 2012). Given these general observations, it is striking that over the past ten thousand years, following the stabilization of the climate in the Holocene, most human communities have transitioned to a type of social organization characterized by spatial agglomeration and the growth of regional urban systems (Glaeser 2011; Jacobs 1969; Wrigley 2016; De Vries 1984; Morris 2013; Ucko, Tringham, and Dimbleby 1972; Fletcher 1995).

Settlement scaling theory-the systematic study of how population size is related to other socioeconomic and physical characteristics of human aggregations-builds upon the observations, long recognized in anthropology and related fields, that population size is both a determinant and a consequence of human social development, and that settlement size is a strong correlate of the rates and magnitudes of many social and ecological processes in human societies (Carneiro 2000; Chamberlain 2006; Johnson and Earle 2000; Renfrew 1972; Turchin et al. 2018; Chick 1997). Here we focus on how the areal extent of an agglomeration changes as the 
population size of that agglomeration changes. Although this is a simple and straightforward relationship, it is revealing of deeper dynamics because the area occupied by a human group relative to its population is itself indicative of the behaviors and cultural institutions that structure interactions among the individuals involved. The relevant theory has been explored widely with regard to sedentary agglomerations (Bettencourt 2013; Ortman et al. 2014; Bettencourt 2014). Here, we extend this framework to encompass short and longer-term H/G agglomerations.

In the following sections, we first review a series of factors that influence the size and density of $H / G$ camps. Then, we propose some simple quantitative theory that addresses conditions that require mobility vs. sedentism and the effects of interaction and social distance for camp density. Taken together, our results suggest that permanent settlements create opportunities for the intensification of human interactions, and associated socioeconomic and cultural outputs, in ways that are not characteristic of mobile H/G adaptations. The manifestly different manner in which $\mathrm{H} / \mathrm{G}$ groups express their sociality in residential space suggests that they typically lack certain social and material innovations that allow humans to live at greater spatial densities in permanent settlements. In this way, sedentism would appear to be a key indicator of the advent of specific social and cultural innovations that support population growth, technological innovation and, in some cases, increasing material output, investment and elaboration..

\section{Human Sociality and Physical Space}

At the most fundamental level, we take human societies to be groups of people integrated by relationships, contacts and exchanges embedded in physical space (at least until very recently). As a consequence, the resulting spatial properties of human groups reflect the character of the interactions through which individuals accrue net benefits from others. In many 
small-scale societies there is a strong relationship between social distance and physical distance, such that friends and relatives reside nearer to each other than newcomers, strangers or outcasts do (Wiseman 2014, 2016). So although proximity facilitates and implies more frequent contact (Hill et al. 2011; Hill et al. 2014), it may also signal a difference in the type of social interaction involved. This relationship also signals that interactions between strangers, on larger spatial scales, need to be managed. All social interaction requires movement and communication across space and therefore entails an expenditure of time and effort, that is, it has an energetic cost. Physical distance also affects the senses, as vision, hearing, smell and touch all decay with distance (Hall 1966; Moore 1996). As a result, one would expect the spatial organization of both temporary camps and permanent settlements to reflect patterns of communication, interaction and residential group integration.

Among documented hunters and gatherers there is a great diversity of lifeways, from small and highly-mobile groups following seasonal migratory patterns to large semi-sedentary and even sedentary groups that specialize in the management and storage of key resources as dietary staples (Kelly 2013; Ames 1994). This diversity of lifeways can be encapsulated in the different manners in which H/Gs deal with risk and uncertainty in their environments; that is, whether they use social techniques of risk sharing or rely heavily on storage (Wiessner 1977; Woodburn 1982). While conflating multiple characteristics, the literature broadly polarizes/dichotomizes these two modes of living as mobile vs. complex hunter-gatherers, respectively, a simplified distinction followed here.

Gould and Yellen (1987) focus on the determinants of household spacing in mobile H/G camps, a feature that ultimately determines the areal extent of camps. They identify the following factors: construction technology, resource endowments, climate, household interdependencies, 
degree of relatedness among members of different households, defense from predation and group size. In addition to these, cooperative breeding and child-rearing also affect patterns of proximity (Hrdy 2009; Kramer 2010; Lee 2018). Some but not all of these factors have counterparts in permanent settlements, including cities.

Although mobile H/Gs do aggregate periodically, camps typically consist of just a few families. Most camps are ephemeral, being occupied for days or weeks and rarely for more than a season. The basal units of these camps are nuclear families that sleep in the same shelter (huts, tents, windbreaks, etc.) and associate strongly on a daily basis with other members of their extended family and with a small number of other families camping nearby. Small groups of extended families also regularly associate with one other, sharing access rights to a particular territory that they exploit for its plant and animal resources. Others can gain access to these areas if they maintain appropriate social ties. Accordingly, camps change in composition as visitors come and go. The resulting groups, often referred to as bands, usually contain 20-30 individuals (Kelly 2013).

In larger camps extended families usually camp in a relatively dense cluster, with open space between additional extended-family clusters. If multiple bands come together for sharing, exchanging, socializing, and/or other activities, each band tends to stay distinct, camping somewhat apart from the others (Shott 2004; Kelly 2013). For example, in Plains Indian aggregation sites, the members of each individual band located their shelters in a cluster, spatially set off from other such clusters (Hassrick 1964; Banks and Snortland 1995). Each level of social group in a camp behaves essentially as a distinguishable module whose identity is represented and reinforced via spatial distancing from other modules (Hamilton et al. 2007). Thus, assembling a camp entails a process where modules are not simply added, but are placed 
more loosely together, with extra spatial buffering between them. This pattern suggests that, in general, the population density of $\mathrm{H} / \mathrm{G}$ camps should decrease as the number of families (modules) who are camping together increases (Whitelaw 1991, 1994).

An additional factor that appears to influence the density of $\mathrm{H} / \mathrm{G}$ camps is the interface between subsistence and human psychological predispositions. In most H/G societies there is a norm of food sharing, where camp mates can ask for food with the expectation of being given some, with only a general obligation to reciprocate in the future (Kelly 2013; Woodburn 1982; Kaplan and Hill 1985). This is especially true for foods that come in large packages. For close kin, a norm of generalized food sharing is consistent with the concept of "kin selection" in the evolutionary theory of cooperation (Hamilton 1963, 1964, 1964; Trivers 1971), but as the camp grows in population the average relatedness and familiarity between individuals will decline. As a result, individuals often do not want to share with everybody, even when they could (Dyble et al. 2016; Schnegg, 2016). The easiest way to regulate the frequency of solicitations from camp mates is through the insulation of physical distance. Willingness to share is also affected by other considerations, such as food risk, resource package size and preservability. Still, other important aspects of human sharing, namely cooperative child-rearing would have been facilitated by households' proximity within camps (Hrdy 2009; Kramer 2010; Lee 2018). These factors, in combination with the management of sharing as a social norm, should favor decreasing camp density as camp population increases.

Finally, as with any human society, H/G groups must manage, minimize and resolve conflict within the group. Mobile foraging societies have many social mechanisms for conflict avoidance such as mediation, rules that structure relationships and specify with whom one may joke, or to whom one must show deference. However, in the face of severe conflict most H/Gs 
disperse spatially until tempers cool. The most salient contrast with societies having permanent or semi-permanent settlements is that the latter have a variety of social conventions or formal institutions to manage conflict without dispersal, as well as physical infrastructures (i.e., walls, enclosed dwellings, household compounds), which shield individuals and their property from others, thereby reducing potential conflicts (Whitelaw 1991, 1994; Bowles and Choi 2013; Kuijt 2000, 2008). These social institutions and physical infrastructures decrease the costs of close proximity and open up possibilities for other forms of interdependence and interaction between people who are not closely related.

\section{Spatial arrangements in mobile $H / G$ camps: a model}

We now turn to the quantitative consequences of the features of social relations and spatial arrangements in $H / G$ camps discussed above. We acknowledge debates concerning the use of recent H/G groups as models for "prehistoric" foragers (Wilmsen 1989; Lee 1992; Lee and Guenther 1995; Marlowe 2005) but take it as uncontroversial that ethnographicallydocumented mobile H/Gs lived a non-sedentary lifestyle and thus present a clear contrast to more sedentary societies (both past and present). In this context, we show that basic spatial properties of camps can be understood using simple considerations of: 1) density-dependent costs (including energy requirements) and social interactions; 2) resource availability; and 3) the translation of social distance between groups and individuals, based on kinship and familiarity, into physical distance inside a camp. The resulting framework leads to several expectations regarding the relationship between camp population and area that we explore using ethnographic information in the remainder of the paper.

Anthropologists who have examined spatial arrangements within H/G camps have generally not observed the in-filling of physical space—physical structures and the establishment 
of open communal space-characteristic of permanent settlements (Turnbull 1961, 1966; O'Connell 1977; Gargett and Hayden 1991; Binford 1991; Memmott 2002; Yellen 1977). Rather, households tend to arrange themselves spatially in ways that regulate interaction and permit some privacy. Rather than seeing residual organisations that adapt over the medium and longer term to already established physically defined spaces, the frequent re-establishment of the camps by mobile foragers makes it easier to see the mappings of social relations onto space.

A well-known arrangement, described by Wiessner (1974) for mid-20 ${ }^{\text {th }}$ century San (Ju|'hoansi) camps, is a “perimeter-area” occupancy pattern. In this arrangement, households camp on the perimeter of the camp, typically an approximation to a circle, and may use the corresponding circumscribed area as social interaction space. In this circumstance, as noted by Wiessner, the population of the camp, $N$, will be distributed along the length of the perimeter, which can be approximated as the square root of the camp's area so that $N \sim A^{1 / 2}$. Thus an expression for area as a function of population is $A(N)=a N^{2}$, with the constant $a$ (the intercept when the equation is linearized by taking the logarithm of both sides of the equal sign) representing, in an idealized limiting case, the area taken up by a single shelter. The consequence of this spatial arrangement is that, as the group size increases, the area $A$ grows proportionately to the square of the population, such that the population density $(n=N / A)$ decreases rapidly: $N / A$ $=N / N^{2}=1 / N$. This de-densification helps to regulate potential conflicts, while still allowing for some beneficial interactions. However, this area-perimeter spatial arrangement does not appear to characterize most (particularly smaller) H/G camps and the empirically-observed exponents for the population-area relationship are typically less than two, as we show below. It might be that such interaction spaces are not required in small camps of an extended family. 
There are three general features of obile $\mathrm{H} / \mathrm{G}$ spatial behavior that we seek to capture in a more general model: 1) temporality, with a fission-fusion dynamic in camp size tailored to patterns of resource availability and use; 2) the general decrease in density of camps with increase in population size; and 3) a spatial arrangement within camps where more related groups (in biological and social terms) camp closer together than less related groups. We will see that, taken together, these three phenomena can be incorporated into a framework that highlights the conditions under which we might expect H/G groups to transition from temporary camps to more permanent settlements. The models that follow are not intended to predict the exact realized properties of individual camps, but average relationships among properties across camps. We would expect additional, contextual factors to impact the extent to which these average relationships are apparent in specific instances.

We first consider factors that encourage group camping vs. dispersal. We begin by noting that, regardless of the detailed spatial arrangement of people in a foraging area, the average per capita rate of energy capture from foraging, $r_{E}$, and the average per capita rate of social interactions, $r_{S}$, are both dependent on population density. With an increase in density, the social interaction rate $r_{S}$ can be expected to increase as social encounters become more probable. However, with respect to the rate of energy capture, $r_{E}$, there is likely an initial increase with density (based on sharing information about the location of resources and the coordination of foraging activities) but then a rapid decline through competition as people exploit the same resources of the local environment. At higher densities one would expect this to happen more rapidly because the same mobility limits (effective daily foraging radius) apply to all people, regardless of the population size. 
The per capita rates of energy capture and of social interactions can be described as the time derivatives of energy capture, $E$, and of the output, $S$, resulting from social interactions:

$$
\frac{d E}{d t}=r_{E}=r_{0}-k \frac{N}{A}, \quad \frac{d S}{d t}=r_{S}=G \frac{N}{A}-r_{c},
$$

where $G$ denotes the (ultimately also energetically bound) benefits from social interactions, $r_{0}$ is a baseline rate of individual-level energy use, $r_{c}$ is the limiting cost of engaging in social interactions (see below), and $k$ introduces a carrying capacity effect. (For the sake of tractability $r_{0}, r_{c}, k, G$ are treated as constants with regard to the group size $N$, but may depend on spatial distance, related to the area $A$, as we will show shortly.) The two rates express the simple accounting of the dynamics of accumulation of energy and social products, respectively. The dependence of both energy capture and social productivity on density is explicitly captured by the density term $N / A$ : the $k N / A$ term denotes the interaction between population density and environment carrying capacity while the term GN/A connects the benefits of social interactions with density.

The rates in equation (1) are an instance of the familiar logistic growth (in which change is modulated by density) which can be seen more clearly by rewriting the equations in (1) as

$$
r_{E}=k\left(n_{E}-\frac{N}{A}\right), \quad \text { and } \quad r_{S}=G\left(\frac{N}{A}-n_{S}\right)
$$

where $n_{E}=\frac{r_{0}}{k}$ is the population density at carrying capacity and $n_{S}=\frac{r_{c}}{G}$ is the analogous population density below which maintaining a stock of socially-produced products is not possible. Note that in this framework the rates of "social production” (i.e., collective production, sharing and exchange, contracting marriages, the joint production of knowledge, the arts, festivities and opportunities for cultural transmission) and rates of energy return from foraging have an opposite dependence on population density, such that increasing one decreases the other. These opposed dynamics of social production and energy returns lead to a set of scenarios 
depending on the relative value of the two critical densities, $n_{E}, n_{S}$, representing, respectively, the maximum environmental carrying capacity and the minimum social carrying capacity. Figure 2 illustrates the range of possible relationships between population density, energy production and social production and their consequences for the temporal stability of settlements.

Figure $2 \mathrm{~A}$ shows the situation where the productivity of the environment is relatively low. In this scenario, increasing population density leads to even lower energetic productivity per capita so that individuals will enter a situation of energy production deficit at a density that is lower than the minimum needed for the accumulation of social products (resulting from social interactions). Under these circumstances, in order to obtain a beneficial balance between satisfying energy needs and engaging in social production, individuals must oscillate between situations of production of the first quantity and deficit of the other, and vice versa, as shown in Figure 2B. This situation entails a pattern of periodic group fission and fusion, typical of mobile H/Gs. Figure 2C, on the other hand, shows the situation in a more productive environment, where a population density that supports both energetic sufficiency and positive net social production is possible. In this situation, longer-term camps or even multi-year settlements become possible. For example, if the productivity of the environment varies seasonally, it may be possible to sustain larger camps during periods of higher productivity and then disperse during other seasons. Moreover, if food can be stored locally to bridge the population to the next productive season, year-round settlements become possible. Even in this simple model, there is an echo of the observation that permanent settlements require not only energy sufficiency at a given population density, but also a density that is sufficient to provide net benefits from social interaction and socially coordinated activity. 
We next consider how camp area might be expected to vary with population size when H/Gs camp together. We have seen already that mobile H/G camps exist at population densities at or above which social production can occur, $n \geq n_{S}$; therefore, the dependence of camp density on its population will be at its extreme when the densities of energy consumption and social production are equal, $n_{E}=n_{S}$. The dependence of the average cost of interaction per unit time, $r_{C}$, on the physical size of the camp, can be characterized in terms of the camp's linear spatial dimension (camp “radius”) $R$. On purely dimensional grounds, $[R]^{2}=[A]$, since $R$ is a length and $A$ is the camp's area. There are, of course, benefits of proximity since communication is more effective at close distances. Nevertheless, as Fletcher (1995) notes, the social stresses of interaction also become more acute with close proximity, depending on an individual's social relationships, the context in which interaction occurs, etc. The average cost of interaction can therefore be expected to be affected by camp population in two ways. One is through the cost incurred by moving within the camp. The other cost is the social stress generated by physical proximity to others within the camp. Equation (3) captures these two costs:

$$
r_{c}(R)=\epsilon R+\rho \frac{\ell}{R}
$$

The first term to the right of the equal sign in Equation 3 denotes the physical cost of movement across the camp, where the parameter $\epsilon$ refers to the energy expended moving per unit distance. (In small camps this energy expenditure will be negligible, but in some ecological settings and in larger camps such expenditures can be much larger). The second term to the left of the equal sign is a social-stress related cost, which declines with distance, capturing the (negative) effects of proximity (Fletcher 1995). This second term subsumes costs besides movement that reduce the benefits of proximity (communicable disease, food-sharing demands, conflict, noise, etc.). The parameter $\rho$ translates this net (negative) effect into an additional cost 
and the parameter $\ell$ represents the distance at which proximity costs become significant, which for this effect to be relevant should be in the range of meters.

From Equation 3 a critical camp size, $R *$, can be defined based on the ratio of the proximity costs and the transport costs entailed in interactions: $R_{*}=\sqrt{\frac{\rho \ell}{\epsilon}}$. For a camp size (radius) larger than this critical size, such that $R>R_{*}$, the first effect in Equation 3 dominates and costs are driven primarily by the energetic cost of movement within a camp to participate in social life. In contrast, when $R<R_{*}$, proximity costs related to interaction stress dominate. The average relationship between area (which is proportional to camp size and thus to camp radius) and population for camps can now be estimated by equating the benefits of social interaction with the associated costs, that is:

$$
G \frac{N}{R^{2}}=\epsilon R+\rho \frac{\ell}{R}
$$

Assuming that the benefits and costs of interactions within a camp need to balance, $\epsilon R+\rho \frac{\ell}{R}-$ $G \frac{N}{R^{2}}=0$. By performing some algebraic manipulations on the balanced equation-multiplying through by $R^{2}$, dividing each term by $\epsilon$, and substituting $\rho \frac{\ell}{R}$ with $R_{*}^{2}$-we obtain an equation expressing the balancing of costs and benefits in terms of camp size and camp population:

$$
R^{3}+R_{*}^{2} R-\frac{G}{\epsilon} N=0
$$

The general solution of Equation 5 is shown graphically in Figure 3. It can be seen that when $R \ll R_{*}$, as one would expect in a small camp where proximity stress dominates, the role of $R^{3}$ is minimal, so we can solve for $R$ and square both sides to obtain approximately:

$$
R \cong \frac{G}{\epsilon R_{*}^{2}} N \rightarrow A(N)=A_{0} N^{2}
$$


with $A_{0}=\left(\frac{G}{\epsilon R_{*}^{2}}\right)^{2}=\left(\frac{G}{\rho \ell}\right)^{2}$. This is the "perimeter-area” scaling obtained by Wiessner (1974) for San camps. Conversely, when $R \gg R_{*}$, as occurs when family units are dispersed in separate camps across a foraging territory, the role of proximity stress $R_{*}^{2} R$ becomes negligible, and we can follow the same procedure to obtain approximately

$$
R^{3} \cong \frac{G}{\epsilon} N \rightarrow A(N)=A_{0} N^{2 / 3},
$$

with $A_{0}=\left(\frac{G}{\epsilon}\right)^{2 / 3}$. This result is the typical densification pattern found in permanent settlements, from small villages to large cities, worldwide and throughout history, which has been characterized as the amorphous settlement model (Ortman et al. 2014; Ortman et al. 2015).

One can consider Equation 7 as resulting from a situation where $R_{*} \rightarrow 0$, which entails that proximity costs become much smaller than movement costs and which effectively removes the second term from Equation 3. This would require the presence of social and physical structures, cultural institutions and enforcement mechanisms that support privacy, property ownership and more formal exchanges as a means of overcoming proximity stress (Fletcher 1995). The ethnographic literature reviewed above indicates that proximity stress is relevant for mobile H/Gs, and, as a result, the scaling of camp area with population size should not be scale invariant, but instead exhibit a gradual transition from an exponent of about 2 for situations where individuals reside in small camps to an exponent of about $2 / 3$ in the extreme, or limiting case, if individuals were dispersed evenly across a foraging territory.

The final ingredient for completing the modeling framework is the social distance between residents within camps and its relation to their level of kin-relatedness. If, as argued previously by Whitelaw (1991), mobile H/G camps are generally kin structured, with chains of households related by marriage and kin relationships that are generally reckoned back at most a 
few deceased generations, then the average coefficient of (genetic or fictive kin-based) relatedness between individuals in a camp should decline with group size (Whitelaw 1989:Figure 4.1). This decline in relatedness, and corresponding increase in social distance, leads to a population size dependence of the distance, $\ell(N)$, at which proximity costs become significant (Equation 3). Walker and Hill (2014) compared group size and relatedness, $r$, across H/G groups and found that relatedness does in fact decline with group size according to the expression:

$$
r(N)=r_{0} N^{-\gamma}
$$

with an exponent $\gamma \simeq 1 / 4$, which can be understood as the inverse of the typical family group size (Hamilton et al. 2007). If we take as a given that there is a norm of generalized reciprocity and we assume further that a version of Hamilton's rule $(r B>C$ where $B$ is the reproductive benefit of sharing and $C$ is the reproductive cost associated with sharing) also applies (Hamilton 1963, 1964, 1964), then for any given distribution of resources, the energetic (food) benefits of social contact will decline with group size (Dyble et al. 2016). One would expect social distance to primarily affect the second (proximity) cost term of equation 3 by increasing the distance $\ell$ at which costs begin to be felt.

We are now in a position to describe the distance $\ell$ at which proximity costs begin to be felt in terms of the decay in relatedness with group size, $\ell(N) \sim \frac{1}{k(N)}=\ell_{0} N^{\gamma}$. From here, one can substitute $\ell_{0} N^{\gamma}$ for $\ell$ in the second term of Equation 4, disregard the first term (reflecting the case where $R \ll R_{*}$ and movement costs are minimal), square both sides to turn the radius $R$ into an area, and then solve for area to derive an expression that relates area to group size under these circumstances:

$$
A(N) \simeq\left(\frac{G}{\rho \ell_{0}}\right)^{2} N^{2-2 \gamma} \rightarrow\left(\frac{G}{\rho \ell_{0}}\right)^{2} N^{1.5} \quad(\text { when } \gamma \simeq 1 / 4)
$$


This relation implies that the population density of mobile H/G camps, $n(N)=N / A$, decreases rapidly with group size. As a result, one can divide the group size $\mathrm{N}$ by Equation 9 and simplify (in the case where $\gamma \simeq 1 / 4$ ) to yield:

$$
n(N)=\frac{N}{A(N)} \simeq\left(\frac{\rho \ell_{0}}{G}\right)^{2} N^{2 \gamma-1} \sim N^{-\frac{1}{2}} .
$$

According to equation (10) the rate of density decrease is strongest for populations that are less related (either biologically or through metaphorical extensions of the concept of kinship) and those that tend to camp more densely (such that $R \ll R_{*}$ ) in the first place. In addition, the baseline density is set by the proximity cost $(\rho)$, the baseline distance at which proximity costs are felt regardless of relatedness $\left(\ell_{0}\right)$, and the energetic benefits of interaction $(G)$, all of which may be context-specific.

The modeling framework introduced here specifies a set of conditions that determine: 1) when temporary versus more permanent camps are possible; 2) the density of temporary camps deriving from the combined effects of movement costs and proximity costs; and 3) the effects of social distancing in structuring the layout of camps and their overall area-population relationship. These arguments help us see that both high energy capture and social "productivity" per capita are necessary for the establishment of fixed residence. Our models suggest that both quantities are characterized by finite thresholds, below which a society enters a situation of energetic or social deficit. These alternative patterns can however be managed over time, leading human H/G populations to oscillate between aggregation and dispersal. This framework also suggests that proximity costs related to social and biological distance are a primary impediment to densification of $\mathrm{H} / \mathrm{G}$ camps. We are led to conclude that such costs must be overcome through sociocultural or technological innovations for the open-ended densification regime that characterizes permanent settlements to emerge. Thus, the conditions implicit in sedentism, where 
the net benefits of interaction dominate even as the agglomeration is energetically and socially sustainable, are potentially latent in every H/G society but manifested only incipiently, at different spatial and temporal scales.

The framework developed here leads to several expectations regarding the average relationship between population and area in $\mathrm{H} / \mathrm{G}$ camps that we can now investigate empirically. First, while we would expect the exponent of the scaling relation to be between one and two in most situations, we would not expect it to have any particular value since this value should vary with scale, strength of proximity stress, and degree of relatedness across contexts. These too are testable hypotheses. Second, we would expect this exponent to exhibit a curvilinear relationship with scale overall. It should be between about 1.5 and 2 for the regime where $R<R_{*}$ and proximity costs and social distance dominate, but it should decline as $R>R_{*}$ and transport costs come to dominate over proximity costs (Equation 4). Third, in cases where storable resources and storage technology provide a sustainable energetic return and sociocultural institutions reduce the social stress between neighbors, one would expect the scaling exponent to approach the value observed in permanent settlements and become less than unity.

\section{Empirical Analysis of H/G Camps}

To test these expectations, we utilize a database representing 1,760 H/G camps from 112 different cultural groups and a variety of regional and ecological settings (Whitelaw 1989, 1991, 1994). Construction of this dataset was possible because many ethnographic works include an example community plan, a normative camp sketch, or simply a description of the community where the ethnographer worked, as part of the background documentation. These ethnographic reports were published throughout the $20^{\text {th }}$ century. While often not explicitly discussed in the text, such documentation allows the characterization of camp layout, habitation density, and 
group size. The information in the primary sources ranges from detailed ethno-archaeological plans of debris on occupation sites to small scale sketch maps or written descriptions. In the case of aboriginal California, researchers calculated figures for normative "seasonal village" population size and areal extent based on archaeological data, explorers' accounts and ethnohistoric data (Cook and Heizer 1968).

The groups represented reflect a variety of natural habitats, food acquisition and storage technologies, and socio-cultural behaviors. Community population estimates were ranked from the most to the least reliable based on the following scale: 1) a census made at the same time as the plan; 2) the ethnographer's rough estimate, or an official census of about the same date as the plan; 3) an estimate usually based on the number of structures and the average number of occupants per shelter for that culture; and 4) essentially an informed guess based on likely family size and the number of structures. The areas of camps (measured in square meters) were either directly reported or estimated from scaled maps. Ranked in terms of reliability, sources were: 1) a detailed ethno-archaeological plan; 2) an ethnographer's rough plan; 3) a small-scale plan; 4) an unscaled sketch; and 5) verbal descriptions or tabled figures. The assembled data for each camp also includes information on the cultural group represented (as noted in the original report) and the degree to which the community followed traditional social and economic behaviors, as well as an ecological (arctic, subarctic, desert, savanna, temperate, and tropical forest) and regional (Asia, equatorial Africa, southern Africa, Australia, Greenland, North America, and South America) classifications.

Site areas were based on the residential area of a camp, defined as a convex hull polygon connecting points 0.5 meters beyond the perimeter of any residential structure. These areas were measured by a CAD program for all camps with plans. A minimum threshold size of two 
structures (or nuclear families) was imposed for including an observation in the analysis, on the argument that two would be the smallest number of nuclear families for which one might expect the balancing of costs and benefits to come into play in a camp's spatial arrangement. It is further assumed that a camp population of six individuals corresponds to two families so the observations used in the study all have a population greater than or equal to six individuals. In addition, there was a concern that many of the communities in the original data set were "nontraditional" in the sense that their social and economic situation no longer represented a coherent indigenous, subsistence-oriented social and spatial adaptation. Some of the communities in the dataset were actually permanent settlements, laid-out by missions or government settlement projects, and so should not be used as examples of mobile communities (although members of these communities still forage or engage in limited hunting or foraging expeditions). Since all modern $H / G$ populations are living at the fringes of the world economy, interaction with the cash-based economy or a national welfare system erodes "traditional" (pre-contact) patterns of social and economic relationships. To avoid these confounding issues, we pruned the original dataset by removing communities that were spatial sub-segments of a larger settlement, nontraditional aggregate groups, or relied significantly on non-subsistence economic activities. These pruning exercises resulted in a dataset with 1,209 observations of which 748 denote mobile camps and 461 correspond to permanent or semi-permanent settlements. For a discussion of how "traditional” H/G communities were identified see Whitelaw (1989).

Summary statistics for camp area, population size and camp area per person are shown in Table 1 for the full and "mobile" datasets. The summary statistics convey the great diversity of camp life among the H/G groups covered by the data. Figure 4 shows the relationship between the camp area (measured in square meters) and camp population for all of the observations 
(variables expressed in natural logarithmic form). The pattern of increasing area with increasing population is clearly visible, as is the gradual decline in the slope of the relationship with camp population (and thus length, $R$ ).

\section{Estimation Framework and Results}

The average relationship between camp area $(A)$ and population size $(N)$ is represented using a power-function, $A=c N^{\beta}$ (Wiessner 1974; Bettencourt 2013). Estimates for the exponent $\beta$ can be obtained via linear regression by first taking the natural logarithm of the power-function equation:

$$
\ln A=c+\beta \ln N+\varepsilon
$$

and then using equation (12) as the basis for a regression estimation exercise, with the term $\varepsilon$ denoting fluctuations with a finite variance and zero mean over the population of observations. Under equation (12), a $1 \%$ increase in population is associated with an average $\beta \%$ increase in camp area. The basic estimation method used is ordinary least-squares regression, augmented with controls for heteroscedasticity and generalized least-squares to control for fixed effects. In all cases in which fixed-effects estimation was used, the results were unchanged when using generalized least-squares with a large dummy-variable set (all estimations were carried out using the STATA SE version 14 software package). The scaling relationship is described as superlinear when $\beta$ is greater than 1 , linear when it is equal (or almost equal) to 1 , and sublinear when it is less than 1 .

Note that we investigate only the average relationship between camp population and area. There is obviously substantial variation in the density of individual camps due to a host of contextual factors, from cultural tradition to ecological and topographic context to the specific 
compositions of individual camps and other stochastic factors. The effects of these factors are summarized in the residual, $\varepsilon$, for each camp away from the regression line.

Table 2 presents estimation results for several different models which utilize all 1,209 observations. Model 1 includes all the observations, while models 2, 3 and 4 present regression results when using the ecological setting, continental location, and cultural affiliation as fixedeffects controls. Models 2-4 attempt to account for the manner in which ecological setting, resource utilization, foraging and storage technology, and socio-cultural practices specific to each group modulate the relationship between camp area and group size (for explorations of these variables, see Whitelaw 1989, 1991). Table 3 presents a series of additional models using observations only for the fully mobile $\mathrm{H} / \mathrm{G}$ communities. These observations correspond to communities which are highly mobile, rely on extensive sharing of resources, and form camps consisting of clusters of co-operating families. Model 5 uses all 748 observations for mobile groups with models 6 through 8 controlling for ecological and regional settings and cultural affiliation, respectively. The estimated scaling coefficient for both the full set of observations and the mobile groups are similar (and superlinear), and robust to the environmental, regional and cultural affiliation controls.

Models 9 to 13 (in Table 4) present the relationship between camp area and group size for distinct mobile H/G lifestyles. Arctic and Sub-Arctic communities (Alaska, Canada and Greenland) usually have wider inter-dwelling spacing and thus have lower densities than lower latitude groups (notwithstanding how substantial Inuit winter dwellings can be). These are primarily hunters who rely on individual household hunting and storage rather than extensive sharing between families. The desert communities are mainly Australian desert groups, which are highly mobile, engage in limited sharing of subsistence resources, and maintain low density 
communities. The savanna observations represent principally San groups from the central Kalahari, and north Australian Aboriginal groups. Temperate communities, predominantly in California and along the West Coast of the United States and Canada, are often larger and more permanent communities with more complex social organization. Tropical forest communities are mostly from central Africa and South America. These are also highly mobile, generally with a high degree of sharing of resources in the residential group, and some co-operative hunting (e.g., net-hunting, game drives).

These estimation results show a range of scaling relationships between residential camp area and group size. In general, the relationship is very similar for the entire sample and the subset of traditional communities. There are clearly superlinear scaling coefficients $(\beta>1)$ across the entire dataset and for most controls examined. As expected, the actual value of the scaling coefficient varies across models, but most are in the vicinity of 1.5, as predicted by the model that includes proximity stress and kin-selection effects, Equation 8 . This pattern contrasts strongly with the densification regime which characterizes permanent settlements and further suggests that, in contrast to settled societies, social interaction in mobile $\mathrm{H} / \mathrm{G}$ societies generally exhibits decreasing returns to scale. Collectively, these results suggest that the emergence of social and economic conditions that supported permanent settlements was a major watershed in human development that made possible the open-ended accumulation of social products, in the form of stocks of knowledge and goods.

Our second expectation for the overall relationship between population and area is supported by Figure 4 (corresponding to model 1), which shows that the population-area relationship in mobile $\mathrm{H} / \mathrm{Gs}$ is not scale-free as the plot shows a somewhat curvilinear relationship: the fit line at the upper tail of the scatter plot would exhibit decreasing slope, 
consistent with the hypothesis that as camp size increases, proximity costs will gradually give way to transport costs as the dominant factor behind the spatial arrangement of shelters. Finally, our third expectation for the relationship between population and area is supported by Models 14 to 17 (Table 5), which show the results for several groups with distinctive lifestyles: the San from southern Africa (model 14), communities from the North American Pacific Northwest including the Haida, Kwakiutl, Nootka and Tlingit (model 15), a broad Northwest Coast behavioral group (model 16, covering the NW Coast, Northern California and Western Coastal Alaskan groups, including the Ingalik, Koyoukon and Tanaina); and various groups from California (model 17). The California grouping includes communities living in coastal, inland and riverine environments, predominantly in semi-sedentary winter villages which almost invariably had substantial timber houses that insulated each residential group and more complex social organizations that regulated interactions among groups. For the set of observations corresponding to the San of southern Africa the estimated scaling coefficient is close in value to 2, as reported previously by Wiessner (1974) using a smaller sample, including only small camps.

The scaling coefficients for the Northwest North American Coast and California are noteworthy, with the coefficient for groups living in California being nearly linear, and the coefficient for the Northwest Coast being strongly sub-linear, with a value close to that exhibited in other sedentary societies. These two groups represent "complex" H/G societies in which aggregations are not properly referred to as camps, but as semi-permanent or permanent settlements. This result is revealing because, of all the groups in the database, those living in Northern California and the Pacific Northwest at the time of ethnographic documentation lived in a manner exhibiting many of the trappings of sedentary life, most importantly access to 
reliable, predictable and abundant energy sources (Jorgensen 1980; Bean and Blackburn 1976; McFeat 1989). Mollusk collecting, harvesting of salmon and acorn stocks, organized communal near-shore hunting of sea mammals, hunting of deer, gathering of nuts and berries, and developed storage technologies all made it possible for societies on the Northwest Coast of North America to support semi-permanent or permanent settlements that were inhabited for multiple years (Ames 1994; Jorgensen 1980). Spatial plans of these communities indicate that they generally grew by expanding along a river or shorefront. The sublinear relationship between population and area suggests that in larger settlements large houses were spaced more closely together, contained more people per house, or both. Groups with larger communities correlate with greater frequency of warfare, so larger individual house groups and denser packing of houses may also be a response to inter-community conflict.

The densification rates exhibited by communities of the Pacific Northwest and California are similar to those observed in agricultural and urban societies, suggesting that these groups used residential space in similar ways to sedentary, agrarian groups. This further suggests that it is not agriculture per se, but more basic energetic and social factors (factors related to resource abundance and predictability, food storage, and socioeconomic regulation of rights and obligations) that are likely most responsible for the shift from a decreasing density regime characteristic of mobile camps to an increasing density regime characteristic of sedentary settlements.

\section{Discussion}

The empirical results presented here reinforce previous studies which have found that mobile H/G camps generally become less dense as they grow in population (Wiessner 1974; Fletcher 1990; Whitelaw 1991; Hamilton, Buchanan, and Walker 2018). This general result 
implies that, among mobile $\mathrm{H} / \mathrm{Gs}$, rates of some energetically-relevant interactions between camp residents decline, on average, with camp size. The most important contribution of the present discussion is a modeling framework which places the social use of physical space at the center of explaining why mobile H/G camps de-densify with increasing population whereas semi-permanent $\mathrm{H} / \mathrm{G}$ communities and permanent settlements exhibit the opposite tendency. This suggests that physical space (the spacing between residences and between socially-coherent clusters of residences) is used in $\mathrm{H} / \mathrm{G}$ communities both to facilitate interaction among close relations, and also to create privacy and regulate interaction with more socially distant persons, without incurring the cost of building more substantial housing and fencing in a highly mobile context (Whitelaw 1989, 1991, 1994).

Our formal models indicate that the de-densification regime documented for mobile H/Gs derives from a combination of proximity tensions in situations where the built environment provides only limited privacy. In addition, the carrying capacity of locally available resources is an important determinant of camp size and permanence, both of which may create more propitious conditions for social arrangements to develop and eventually sustain sedentary lifestyles. The specific de-densification pattern which characterizes mobile H/G camps is radically different from that documented for permanent, agriculture-based settlements across a wide range of sedentary societies. From small subsistence farming villages to contemporary cities, agriculture-based settlements tend to grow denser with population (i.e., area-population scaling coefficient $<$ ), generally with scaling coefficients between 2/3 and 5/6 (Ortman et al. 2014; Bettencourt 2013; Ortman and Coffey 2017; Ortman et al. 2016). These qualitative and quantitative differences point to the existence of constraints that lead to increasing spacing between individuals in mobile $\mathrm{H} / \mathrm{G}$ camps. 
From this perspective, the dynamics of de-densification in $\mathrm{H} / \mathrm{G}$ camps is a mechanism for foragers to experience the benefits of spatial agglomeration within the constraints of their social conventions, physical technologies and economic (energetic) productivity. But if this were the only barrier to agglomeration, one might expect agrarian settlements in a densification regime to expand exponentially, ad infinitum. That this does not occur easily demonstrates that there are additional factors that limit the scale of human agglomerations. Cross-cultural work by Narroll (1956), Dumond (1965), Carneiro (1967), Fletcher (1990, 1991, 1995), and Forge (Forge 1972), suggest some of the additional factors—-technological, social and psychological—that constrain the advantages of density in small-scale agrarian and horticultural societies. This implies that several constraints, in addition to energetics, limit the scale of functionally interdependent social networks embedded in physical space.

The theoretically-derived scaling results reported here suggest that the "social reactor" process that characterizes permanent, agriculture-based settlements is not a "universal" feature of human sociality or an expression of some intrinsic set of evolved psychological predispositions, but a dynamic that emerged in tandem with the energetic and social conditions that made sedentism possible. The fact that complex $\mathrm{H} / \mathrm{Gs}$ create settlements that exhibit similar population-area scaling relationships as agrarian and industrial societies suggests that the key factors that enabled the transition from a de-densification to a densification regime do not necessarily involve domesticated food production, although they do involve surpluses and storable resources.

H/G societies abound in norms and rules (social infrastructure) that make it possible for individuals to live in close spatial proximity to biological non-kin or socially distant individuals (Wiessner 2014). H/Gs also come together seasonally in relatively large, temporary, gatherings 
to arrange marriages and to forge and maintain social networks that extend far beyond the typical camp. In this context, the transition from mobility to sedentism clearly built upon foragers' experience devising ways for more distant kin and non-kin to agglomerate. However, while both mobile $\mathrm{H} / \mathrm{Gs}$ and sedentary societies have complex social and material networks, the agglomeration of networks in space in sedentary societies requires innovations in built infrastructure and social institutions that allow people to live together permanently in relative harmony. These innovations, in turn, provide frameworks for increasing social complexity.

If an effort to model the social and technological correlates of spatial behavior is empirically supported, the model can then generate hypotheses about past social behaviors and institutions represented in the archaeological record, hypotheses which can be contextualized with other data sources. The theoretical and modeling frameworks presented here are intended to help clarify the social factors that lead some horticulturalists/ agriculturalists to space their settlement widely and others to densify. For urban studies there are certainly different spatial configurations of settlements and the model presented may help identify the fundamental social factors and institutions behind the variations in social behavior as revealed in settlements.

\section{Acknowledgements}

Portions of this research were supported by the James S. McDonnell Foundation (\#220020438), the Arizona State University - Santa Fe Institute Center for Biosocial Complex Systems and the Mansueto Institute for Urban Innovation at the University of Chicago. 


\section{References}

Ames, Kenneth M. 1994. The Northwest Coast: Complex Hunter-Gatherers, Ecology, and Social Evolution. Annual Review of Anthropology 23:209-229.

Banks, K. M., and J. S. Snortland. 1995. Every Picture Tells a Story: Historic Images, Tipi Camps, and Archaeology. Plains Anthropologist 40:125-144.

Bean, Lowell John, and Thomas C. Blackburn, eds. 1976. California Indians: A Theoretical Retrospective. Menlo Park, CA: Ballena Press.

Bettencourt, Luis M. A. 2013. The Origins of Scaling in Cities. Science 340:1438-1441.

2014. Impact of Changing Technology on the Evolution of Complex Informational Networks. Proceedings of the IEEE 102 (12):1878-1891.

Binford, Lewis R. 1991. When the going gets tough, the tough get going: Nunamiut local groups, camping patterns and economic organisation. In Ethnoarchaeological approaches to mobile campsites. Hunter-gatherer and pastoralist case studies, edited by C. S. Gamble and W. A. Boismier. Ann Arbor: International Monographs in Prehistory.

Bloom, David E., David Canning, and Gunther Fink. 2008. Urbanization and the Wealth of Nations. Science 319:772-775.

Bowles, Samuel, and Jung-Kyoo Choi. 2013. Coevolution of farming and private property diring the early Holocene. Proceedings of the National Academy of Science of the U.S.A. 110 (22):8830-8835.

Bowles, Samuel, and Herbert Gintis. 2011. A Cooperative Species: Human Reciprocity and Its Evolution. Princeton: Princeton University Press.

Carneiro, Robert L. 1967. On the Relationship Between Size of Population and Complexity of Social Organization. Southwestern Journal of Anthropology 23:234-243.

2000. The transition from quantity to quality: A neglected causal mechanism in accounting for social evolution. Proceedings of the National Academy of Science of the U.S.A. 97 (23):12926-12931.

Cavalli-Sforza, L. L., Paolo Menozzi, and Alberto Piazza. 1994. The history and geography of human genes. Princeton, N.J.: Princeton University Press.

Chamberlain, Andrew. 2006. Demography in Archaeology. Cambridge: Cambridge University Press.

Chick, Garry. 1997. Cultural Complexity: The Concept and Its Measurement. Cross-Cultural Research 31 (4):275-307.

Cook, Sherburne F., and Robert F. Heizer. 1968. Relationships among Houses, Settlement Areas, and Population in Aboriginal California. In Settlement Archaeology, edited by K. C. Chang. Palo Alto: National Press Books.

De Vries, Jan. 1984. European Urbanization, 1500-1800. New York: Routledge.

Dumond, D. E. 1965. Population growth and cultural change. Southwestern Journal of Archaeology 21:302-324.

Duranton, Gilles, and Diego Puga. 2004. Micro-Foundation of Urban Agglomeration Economies. In Handbook of Regional and Urban Economics, edited by J. V. Henderson and J.-F. Thisse. Amsterdam: Elsevier.

Dyble, Mark, James Thompson, Daniel Smith, Gul Deniz Salali, Nikhil Chaudhary, Abigal Page, Lucio Vinicuis, Ruth Mace, and Andrea Migliana. 2016. Networks of food sharing reveal the functional significance of multilevel sociality in two hunter-gatherer groups. Current Biology 26:2017-2021. 
Fletcher, Roland. 1990. Residential densities, group sizes and social stress in Australian aboriginal settlements. In Hunter-Gatherer Demography, edited by B. Meehan and N. White. Sydney: University of Sydney.

1991. Very large mobile communities: interaction stress and residential dispersal. In Ethnoarchaeological Approaches to Mobile Campsites: Hunter-Gatherer and Pastoralist Case Studies, edited by C. S. Gamble and W. A. Boismier. Madison: International Monographs in Prehistory.

1995. The Limits of Settlement Growth: A Theoretical Outline. New York: Cambridge University Press.

Forge, Anthony. 1972. Normative factors in the settlement size of Neolithic cultivators (New Guinea). In Man, Settlement and Urbanism, edited by P. J. Ucko, R. Tringham and G. W. Dimbleby. London: Duckworth.

Fujita, M., P. Krugman, and A. J. Venables. 1999. The Spatial Economy: Cities, Regions, and International Trade. Cambridge: MIT Press.

Gargett, Rob, and Brian Hayden. 1991. Site structure, kinship and sharing in Aboriginal Australia: implications for archaeology. In The interpretation of archaeological spatial patterning, edited by E. M. Kroll and T. D. Price. New York: Plenum Press.

Glaeser, Edward L. 2011. Triumph of the city: how our greatest invention makes us richer, smarter, greener, healthier, and happier. New York: Penguin Press.

Gould, Richard A., and John E. Yellen. 1987. Man the hunted: determinants of household spacing in desert and tropical foraging societies. Journal of Anthropological Archaeology 6:77-103.

Hall, Edward T. 1966. The Hidden Dimension. Garden City, New York: Doubleday.

Hamilton, Marcus J., Briggs Buchanan, and Robert S. Walker. 2018. Scaling the Size, Structure, and Dynamics of Residentially Mobile Hunter-Gatherer Camps. American Antiquity 83 (4):701-720.

Hamilton, Marcus J., Bruce T. Milne, Robert S. Walker, Oskar Burger, and James H. Brown. 2007. The complex structure of hunter-gatherer social networks. Proceedings of the Royal Society B 274:2195-2202.

Hamilton, William D. 1963. The evolution of altruistic behavior. American Naturalist 97:354356.

1964. The Genetical Evolution of Social Behavior I. Journal of Theoretical Biology 7 (1-16).

1964. The Genetical Evolution of Social Behaviour II. Journal of Theoretical Biology 7:17-52.

Hassrick, R. C. 1964. The Sioux: Life and Customs of a Warrior Society. Norman: University of Oklahoma Press.

Henderson, J. Vernon. 1988. Urban Development: Theory, Fact and Fiction. New York: Oxford University Press.

Henrich, Joseph. 2015. The Secret of Our Success: How Culture Is Driving Human Evolution, Domesticating Our Species, and Making Us Smarter. Princeton: Princeton University Press.

Hill, Kim R., Robert S. Walker, Miran Bozicevic, James F. Eder, Thomas Headland, Barry Hewlett, A. Magdalena Hurtado, Frank Marlowe, Polly Weissner, and Brian M. Wood. 2011. Co-Residence Patterns in Hunter-Gatherer Societies Show Unique Human Social Structure. Science 331:1286-1289. 
Hill, Kim R., Brian M. Wood, Jacopo Baggio, A. Magdalena Hurtado, and Robert T. Boyd. 2014. Hunter-Gatherer Inter-Band Interaction Rates: Implications for Cumulative Culture. PLOS ONE 9 (7):e102806.

Hrdy, Sarah Blaffer. 2009. Mothers and Others: The Evolutionary Origins of Mutual Understanding. Cambridge: Belknap Press.

Jacobs, Jane. 1969. The Economy of Cities. New York: Vintage Books.

Johnson, Allen W., and Timothy K. Earle. 2000. The Evolution of Human Societies: From Foraging Group to Agrarian State. Second ed. Stanford: Stanford University Press.

Jorgensen, Joseph. 1980. Western Indians: Comparative Environments, Languages, and Cultures of 172 Western American Indian Tribes. San Francisco: W. H. Freeman and Company.

Kaplan, H., and K. Hill. 1985. Food Sharing Among Ache Foragers: Tests of Explanatory Hypotheses. Current Anthropology 26:223-246.

Kelly, Robert L. 2013. The Lifeways of Hunter-Gatherers: The Foraging Spectrum. Cambridge: Cambridge University Press.

Kramer, Karen L. 2010. Cooperative breeding and its significance to the demographic success of humans. Annual Review of Anthropology 39:417-436.

Kuijt, Ian. 2000. People and Space in Early Agricultural Villages: Exploring Daily Lives, Community Size, and Architecture in the Late Pre-Pottery Neolithic. Journal of anthropological archaeology 19:75-102.

2008. Demography and Storage Systems During the Southern Levantine Neolithic Demographic Transition. In The Neolithic Demographic Transition and its Consequences, edited by J.P. Boquet-Appel and O. Bar-Josef. New York: Springer.

Lee, Richard B. 1992. Art, Science, or Politics? The Crisis in Hunter-Gatherer Studies. American Anthropologist 94:31-54.

2018. Hunter-Gatherers and Human Evolution: New Light on Old Debates. Annual Review of Anthropology 47:513-531.

Lee, Richard B., and M. Guenther. 1995. Errors Corrected or Compounded? A Reply to Wilmsen. Current Anthropology 36:298-305.

Lees, Andrew. 2015. The City: A World History. New York: Oxford University Press.

Marlowe, Frank W. 2005. Hunter-gatherers and human evolution. Evolutionary Anthropology 14:54-67.

McFeat, Tom, ed. 1989. Indians of the North Pacific Coast. Ottawa: Carleton University Press. Memmott, Paul. 2002. Sociospatial structures of Australian Aboriginal settlements. Australian Aboriginal Studies 2002:67-86.

Moore, Jerry D. 1996. The Archaeology of Plazas and the Proxemics of Ritual: Three Andean Traditions. American Anthropologist 98 (4):789-802.

Morris, Ian M. 2013. The Measure of Civilization: How Social Development Decides the Fate of Nations. Princeton: Princeton University Press.

Naroll, Raoul. 1956. A Preliminary Index of Social Development. American Anthropologist 56:687-715.

Nordbeck, S. 1971. Urban Allometric Growth. Geografiska Annaler 53:54-67.

O'Connell, James. 1977. Room to move: contemporary Alyawara settlement patterns and hteir implications for Aboriginal housing policy. Mankind 11:119-131.

Ortman, Scott G., Andrew H.F. Cabaniss, Jennie O. Sturm, and Luís M. A. Bettencourt. 2015. Settlement Scaling and Increasing Returns in an Ancient Society. Science Advances 1 (1):e1400066. 
Ortman, Scott G., Andrew HF Cabaniss, Jennie O. Sturm, and Luís MA Bettencourt. 2014. The Pre-History of Urban Scaling. PLOS ONE 9 (2):e87902.

Ortman, Scott G., and Grant D. Coffey. 2017. Settlement Scaling in Middle-Range Societies. American Antiquity 82 (4):662-682.

Ortman, Scott G., Kaitlyn E. Davis, José Lobo, Michael E. Smith, Luis M.A. Bettencourt, and Aaron Trumbo. 2016. Settlement Scaling and Economic Change in the Central Andes. Journal of Archaeological Science 73:94-106.

Perreault, Charles. 2012. The Pace of Cultural Evolution. PLOS ONE 7 (9):e45150.

Powell, Adam, Stephen Shennan, and Mark G. Thomas. 2009. Late Pleistocene Demography and the Appearance of Modern Human Behavior. Science 324:1298-1301.

Renfrew, Colin. 1972. The Emergence of Civilisation: the Cyclades and the Aegean in the Third Millennium BC. London: Meuthen.

Schnegg, Michael 2016. Collective foods: situating food on the continuum of private-common property regimes. Current Anthropology, 57: 683-689.

Shennan, Stephen. 2002. Genes, memes and human history: Darwinian archaeology and cultural evolution. London: Thames \& Hudson.

Shott, Michael J. 2004. Hunter-Gatherer Aggregation in Theory and Evidence: The North American Paleoindian Case. In Hunter-Gatherers in Theory and Archaeology, edited by G. Crothers. Carbondale: Southern Illinois University Press.

Smith, Michael E. 2019. The generative role of settlement aggregation and urbanization. In Coming Together: Comparative Approaches to Population Aggregation and Early Urbanization, edited by A. Gyucha. Albany: State University of New York Press.

Trivers, Robert. 1971. The evolution of reciprocal altruism. Quarterly Review of Biology 46:3537.

Turchin, Peter, Thomas E. Currie, Harvey Whitehouse, Pieter François, Kevin Feeney, Daniel Mullins, Daniel Hoyer, Christina Collins, Stephanie Grohmann, Patrick Savage, Gavin Mendel-Gleason, Edward Turner, Agathe Dupeyron, Enrico Cioni, Jenny Reddish, Jill Levine, Greine Jordan, Eva Brandl, Alice Williams, Rudolf Cesaretti, Marta Krueger, Alessandro Ceccarelli, Joe Figliulo-Rosswurm, Po-Ju Tuan, Peter Peregrine, Arkadiusz Marciniak, Johannes Preiser-Kapeller, Nikolay Kradin, Andrey Korotayev, Alessio Palmisano, David Baker, Julye Bidmead, Peter Bol, David Christian, Connie Cook, Alan Covey, Gary Feinman, Árni Daníel Júlíusson, Axel Kristinsson, John Miksic, Ruth Mostern, Cameron Petrie, Peter Rudiak-Gould, Barend ter Haar, Vesna Wallace, Victor Mair, Liye Xie, John Baines, Elizabeth Bridges, Joseph Manning, Bruce Lockhart, Amy Bogaard, and Charles Spencer. 2018. Quantitative historical analysis uncovers a single dimension of complexity that structures global variation in human social organization. Proceedings of the National Academy of Sciences 115 (2):E144-E151.

Turnbull, Colin. 1961. The Forest People. London: Chatto and Windus.

Turnbull, Colin. 1966. Wayward Servants: the two worlds of the African pygmies. London: Eyre and Spottiswode.

Ucko, Peter J., Ruth Tringham, and George W. Dimbleby, eds. 1972. Man, Settlement, and Urbanism. Cambridge, Massachussetts: Schenkman Publishing Company.

Walker, Robert S., and Kim R. Hill. 2014. Causes, Consequences, and Kin Bias of Human Group Fissions. Human Nature 25:465-475. 
Whitelaw, Todd M. 1989. The Social Organisation of Space in Hunter-Gatherer Communities: Some Implications for Social Inference in Archaeology. PhD Dissertation, Faculty of Archaeology and Anthropology, Cambridge University, Cambridge.

Whitelaw, Todd M. 1991. Some Dimensions of Variability in the Social Organisation of Community Space Among Foragers. In Ethnoarchaeological Approaches to Mobile Campsites: Hunter-Gatherer and Pastoralist Case Studies, edited by C. S. Gamble and W. A. Boismier. Madison, WI: International Monographs in Prehistory.

Whitelaw, Todd M. 1994. Order Without Architecture: Functional, Social and Symbolic Dimensions of Hunter-Gatherer Settlement Organization. In Architecture and Order: Approaches to Social Space, edited by M. P. Pearson and C. Richards. London: Routledge.

Wiessner, Polly. 1974. A Functional Estimator of Population from Floor Area. American Antiquity 39 (2):343-350.

Wiessner, Polly. 1977. Hxaro: A Regional System of Reciprocity for Reducing Risk Among the !Kung San. diss, University of Michigan, UMI.

Wiessner, Polly. 2014. Embers of Society: Firelight Talk among the Ju/'hoansi Bushmen. Proceedings of the National Academy of Science of the U.S.A. 111:14027-14035.

Wilmsen, Edwin. 1989. Land Filled With Flies: A Political Economy of the Kalahari. Chicago: University of Chicago Press.

Wilson, David Sloan. 2002. Darwin's Cathedral: Evolution, Religion, and the Nature of Society. Chicago: University of Chicago Press.

Wiseman, Robert. 2014. Social Distance in Hunter-Gatherer Settlement Sites: A Conceptual Metaphor in Material Culture. Metaphor and Symbol 29 (2):129-143.

2016. Social Distance in Settled Communities: The Conceptual Metaphor SOCIAL DISTANCE IS PHYSICAL DISTANCE, in Action. Journal of Archaeological Method and Theory 23 (4):1023-1052.

Woodburn, James. 1982. Egalitarian Societies. Man 17 (3):431-451.

Wrigley, E. A. 2016. The Path to Sustained Growth: England's Transition from an Organic Economy to an Industrial Revolution. Cambridge: Cambridge University Press.

Yellen, John E. 1977. Archaeological Approaches to the Present: Models for Reconstructing the Past. New York: Academic Press. 
Table 1. Statistical summary of the ethnographic dataset for all camps containing at least two shelters and a population equal to or greater than six individuals, and for the subset of fully “mobile” communities.

\begin{tabular}{|r|c|c|c|}
\hline All observations & $\begin{array}{c}\text { Camp Area } \\
\text { (square meters) }\end{array}$ & Population & $\begin{array}{c}\text { Density } \\
\text { (square meters per person) }\end{array}$ \\
\hline Mean & 37,442 & 97 & 211 \\
\hline Median & 1,694 & 34 & 42 \\
\hline Std. Dev. & 226,724 & 168 & 822 \\
\hline CoV & 6.06 & 1.73 & 3.90 \\
\hline Max & $5,193,890$ & 1630 & 16,667 \\
\hline Min & 7.3 & 6 & 0.8 \\
\hline $\boldsymbol{N}$ & 1209 & 1209 & 1209 \\
\hline
\end{tabular}

\begin{tabular}{|rc|c|c|}
\hline \multicolumn{1}{|c}{ Mobile } & $\begin{array}{c}\text { Camp Area } \\
\text { (square meters) }\end{array}$ & Population & $\begin{array}{c}\text { Density } \\
\text { (square meters per person) }\end{array}$ \\
\hline Mean & 9,024 & 42 & 128 \\
\hline Median & 442 & 23 & 19 \\
\hline Std. Dev. & 47,495 & 87 & 669 \\
\hline CoV & 5.26 & 2.07 & 5.23 \\
\hline Max & 436,162 & 1630 & 16,667 \\
\hline Min & 7.300 & 6 & 0.8 \\
\hline $\boldsymbol{N}$ & 748 & 748 & 748 \\
\hline
\end{tabular}


Table 2. Relationship between camp area (dependent variable) and population (independent variable) using all the observations in the dataset for $H / G$ communities (dependent and independent variable in natural logarithmic form).

\begin{tabular}{|c|c|c|c|c|}
\hline \multirow[b]{2}{*}{$\begin{array}{l}\text { std. errors in } \\
\text { parentheses }\end{array}$} & Model 1 & Model 2 & Model 3 & Model 4 \\
\hline & all observations & $\begin{array}{l}\text { controlling for } \\
\text { ecology type }\end{array}$ & $\begin{array}{l}\text { controlling for } \\
\text { regional group }\end{array}$ & $\begin{array}{l}\text { controlling for } \\
\text { culture type }\end{array}$ \\
\hline \multirow[t]{2}{*}{ constant } & 1.225 & 1.846 & 1.955 & 1.476 \\
\hline & $(0.132)$ & $(0.124)$ & $(0.132)$ & $(0.121)$ \\
\hline \multirow[t]{2}{*}{$\beta$} & 1.698 & 1.533 & 1.505 & 1.631 \\
\hline & $(0.034)$ & $(0.031)$ & $(0.034)$ & $(0.031)$ \\
\hline $95 \%$ CI & {$[1.631,1.766]$} & {$[1.471,1.596]$} & {$[1.437,1.572]$} & {$[1.571,1.694]$} \\
\hline $\boldsymbol{R}^{2}$ & 0.68 & 0.78 & 0.76 & 0.89 \\
\hline$N$ & 1209 & 1209 & 1209 & 1209 \\
\hline $\begin{array}{c}\text { estimation } \\
\text { method }\end{array}$ & $\begin{array}{l}\text { OLS w/ a correction } \\
\text { for heteroskedasticity }\end{array}$ & GLS w/ FE & GLS w/ FE & GLS w/ FE \\
\hline
\end{tabular}


Table 3. Relationship between camp area (dependent variable) and population (independent variable) for mobile groups (dependent and independent variable in natural logarithmic form).

\begin{tabular}{|c|cccc|}
\hline \multirow{2}{*}{$\begin{array}{c}\text { std. errors in } \\
\text { parentheses }\end{array}$} & Model 5 & Model 6 & Model 7 & Model 8 \\
\cline { 2 - 5 } constant & mobile groups & $\begin{array}{c}\text { controlling for } \\
\text { ecology type }\end{array}$ & $\begin{array}{c}\text { controlling for } \\
\text { regional group }\end{array}$ & $\begin{array}{c}\text { controlling for } \\
\text { culture type }\end{array}$ \\
\hline $\boldsymbol{\beta}$ & 0.859 & 1.393 & 1.421 & 1.065 \\
\hline $\mathbf{9 5 \%}$ CI & $(0.198)$ & $(0.169)$ & $(0.171)$ & $(0.146)$ \\
\hline $\boldsymbol{R}^{2}$ & $\mathbf{1 . 7 4 2}$ & 1.576 & 1.567 & 1.678 \\
\hline $\boldsymbol{N}$ & $(0.063)$ & $(0.051)$ & $(0.051)$ & $(0.044)$ \\
\hline $\begin{array}{c}\text { estimation } \\
\text { method }\end{array}$ & $\begin{array}{l}\text { OLS w/ a correction } \\
\text { for heteroskedasticity }\end{array}$ & GLS w/ FE & GLS w/ FE & {$[1.591,1.766]$} \\
\hline
\end{tabular}


Table 4. Relationship between camp area (dependent variable) and population (independent variable) for mobile groups in distinct environmental settings (dependent and independent variable in natural logarithmic form).

\begin{tabular}{|c|c|c|c|c|c|}
\hline & Model 9 & Model 10 & Model 11 & Model 12 & Model 13 \\
\hline $\begin{array}{l}\text { std. errors in } \\
\text { parentheses }\end{array}$ & Artic & Desert & Savanna & Temperate & Rain Forest \\
\hline \multirow[t]{2}{*}{ constant } & 1.867 & 2.123 & 0.663 & 3.806 & 1.384 \\
\hline & $(0.326)$ & $(0.547)$ & $(0.284)$ & $(0.406)$ & $(0.212)$ \\
\hline \multirow[t]{2}{*}{$\beta$} & 1.546 & 1.898 & 1.721 & 0.951 & 1.236 \\
\hline & (0.093) & $(0.143)$ & (0.085) & $(0.085)$ & $(0.072)$ \\
\hline $95 \%$ CI & {$[1.362,1.731]$} & {$[1.612,2.184]$} & {$[1.552,1.889]$} & {$[0.771,1.121]$} & {$[1.093,1.378]$} \\
\hline$R^{2}$ & 0.49 & 0.69 & 0.68 & 0.67 & 0.65 \\
\hline$N$ & 222 & 95 & 192 & 104 & 225 \\
\hline $\begin{array}{c}\text { estimation } \\
\text { method }\end{array}$ & $\begin{array}{l}\text { OLS w/ a correction } \\
\text { for heteroskedasticity }\end{array}$ & $\begin{array}{l}\text { OLS w/ a correction } \\
\text { for heteroskedasticity }\end{array}$ & $\begin{array}{l}\text { OLS w/ a correction } \\
\text { for heteroskedasticity }\end{array}$ & $\begin{array}{l}\text { OLS w/ a correction } \\
\text { for heteroskedasticity }\end{array}$ & $\begin{array}{l}\text { OLS w/ a correction } \\
\text { for heteroskedasticity }\end{array}$ \\
\hline
\end{tabular}


Table 5. Relationship between camp area (dependent variable) and population (independent variable) for southern African San and North American Northwest Coast and California groups (dependent and independent variable in natural logarithmic form).

\begin{tabular}{|c|c|c|c|c|}
\hline \multirow[b]{2}{*}{$\begin{array}{l}\text { std. errors in } \\
\text { parentheses }\end{array}$} & Model 14 & Model 15 & Model 16 & Model 17 \\
\hline & San & $\begin{array}{c}\text { Northwest N.A. } \\
\text { Coast }\end{array}$ & $\begin{array}{l}\text { Extended N.W. } \\
\text { North Amenica }\end{array}$ & California \\
\hline \multirow[t]{2}{*}{ constant } & 1.046 & 4.331 & 3.523 & 3.521 \\
\hline & $(0.551)$ & $(0.385)$ & $(0.407)$ & $(0.529)$ \\
\hline \multirow[t]{2}{*}{$\beta$} & 1.955 & 0.744 & 1.12 & 0.99 \\
\hline & $(0.179)$ & $(0.084)$ & $(0.092)$ & $(0.125)$ \\
\hline $95 \%$ CI & {$[1.606,2.304]$} & {$[0.776,1.113]$} & {$[0.949,1.313]$} & {$[0.740,1.242]$} \\
\hline$R^{2}$ & 0.52 & 0.54 & 0.59 & 0.71 \\
\hline$N$ & 104 & 72 & 171 & 54 \\
\hline $\begin{array}{l}\text { estimation } \\
\text { method }\end{array}$ & $\begin{array}{l}\text { OLS w/ a correction } \\
\text { for heteroskedasticity }\end{array}$ & $\begin{array}{l}\text { OLS w/ a correction } \\
\text { for heteroskedasticity }\end{array}$ & $\begin{array}{l}\text { OLS w/ a correction } \\
\text { for heteroskedasticity }\end{array}$ & $\begin{array}{l}\text { OLS w/ a correction } \\
\text { for heteroskedasticity }\end{array}$ \\
\hline
\end{tabular}




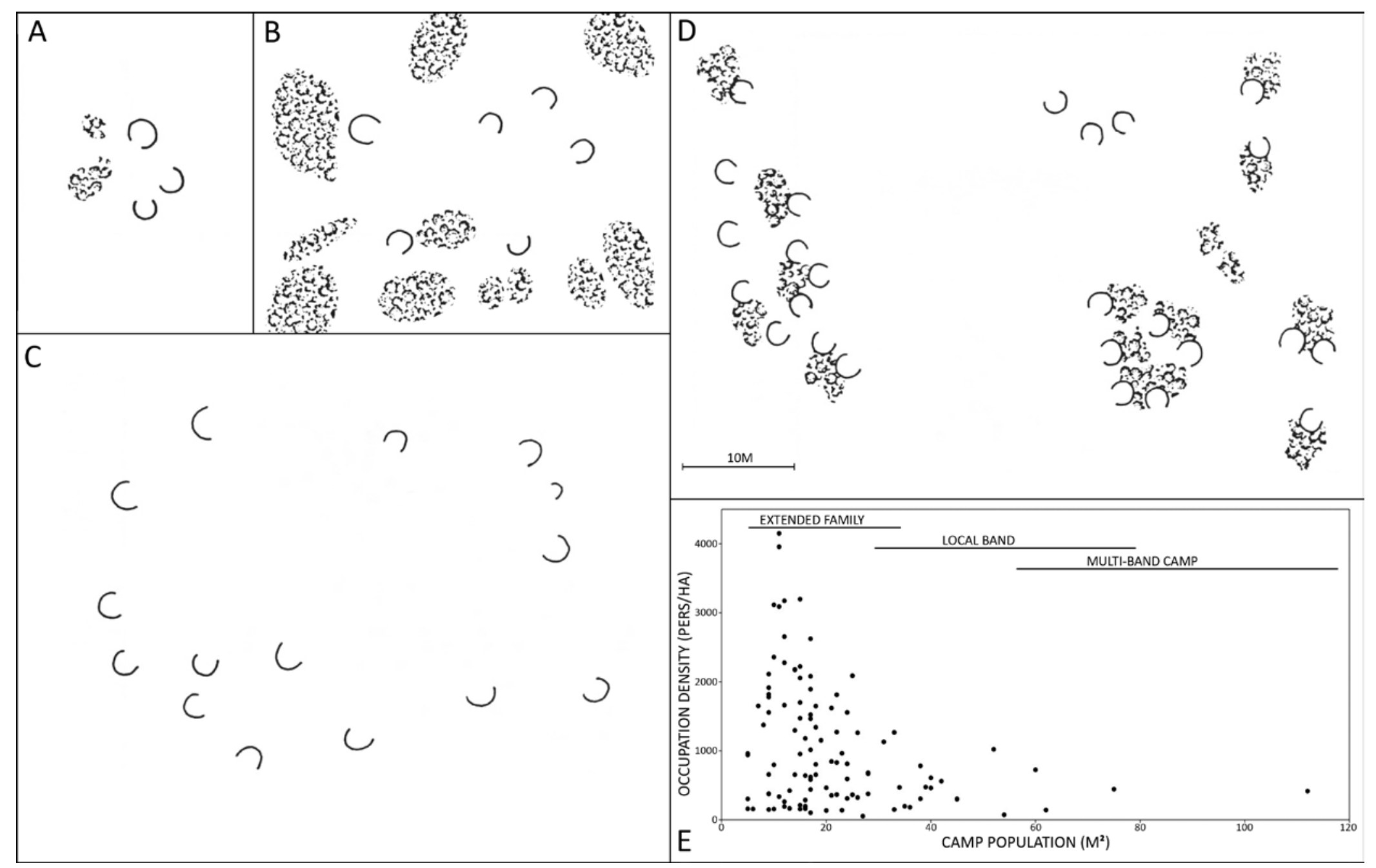

Figure 1. Ju|'hoansi camps. A. - B. extended family camps (Yellen 1977); C. band camp (Brooks, Gelburd and Yellen 1984); D. multi-band camp (Silberbauer 1981); E. occupation density by camp population. 


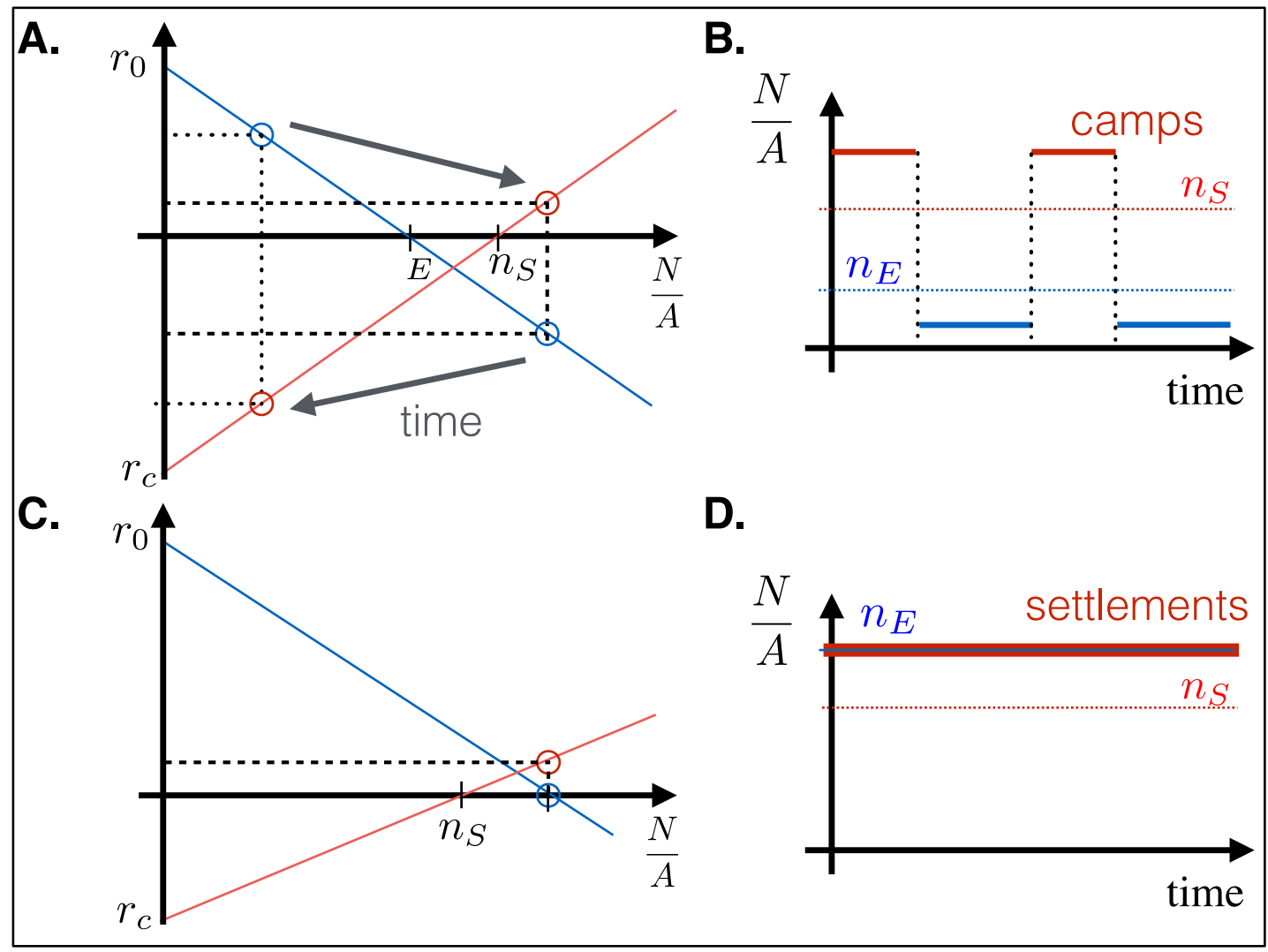

Figure 2. Schematic representation of rates of energy harvesting and socializing versus group density. Figure 2A shows the situation in a relatively unproductive energetic environment. The blue solid line shows the population density dependence of energy production (logistic growth), while the red line shows the rate of social production. In this case, each rate can only be positive when the other is negative. As a consequence there is no static arrangement of population in space (or corresponding fixed density). Instead, Figure 2B, the population must alternate periods of low density when energy harvesting is net positive, but social products decay, with other periods when the opposite is true, and the population experiences short periods of energy deficit in order to socialize. Figure 2C shows a different situation, when energy productivity (red line) is higher. In this case it is possible to find spatial population arrangements that break even in terms of energy and create a net production of social outputs. This makes 
possible permanent settlements for a group of a given size and spatial density, Figure 2D. This situation may be seasonal, associated with higher productivity times and places while they last, or could be more permanent if any seasonal variations can be mitigated e.g. through food storage. Thus, we conclude that longer-term camps and eventually permanent settlements require both energetic and socially favorable conditions, which can be realized in different ways in different physical environments and through cultural/social conventions/structures. Failure to realize break-even (or better) levels of energetic and social production simultaneously will lead to periods of alternating group fission and fusion. 


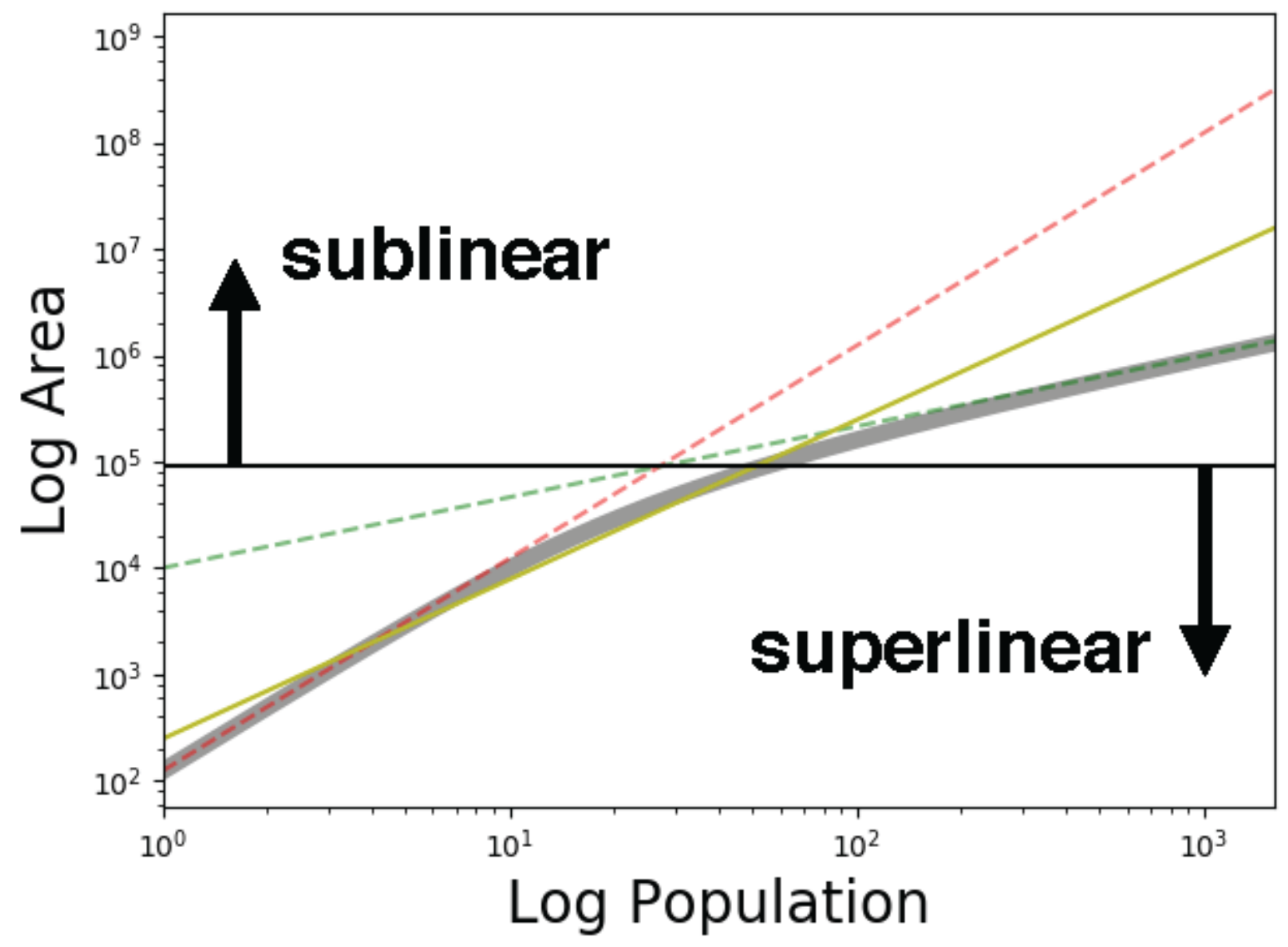

Figure 3. General solution of Equation 4 for the relation between Area and Population.

Camp area increases with the square of camp population (dashed red line) at scales where interaction stress dominates the costs of co-residence, and it increases with camp population to the $2 / 3$ power (dashed green line) at scales where movement costs dominate. The horizontal black line represents the critical area $A_{*}=R_{*}{ }^{2}$ where these lines intersect. This in turn reflects the critical distance $R_{*}$ (or area, solid black line) at which the dominant cost from interaction stress to movement costs. The solid gray line reflects the combined effect of both costs for the population-area relationship. The solid yellow line shows $A \propto N^{1.5}$, which provides a reasonably close fit for small camps where interaction stress dominates. 


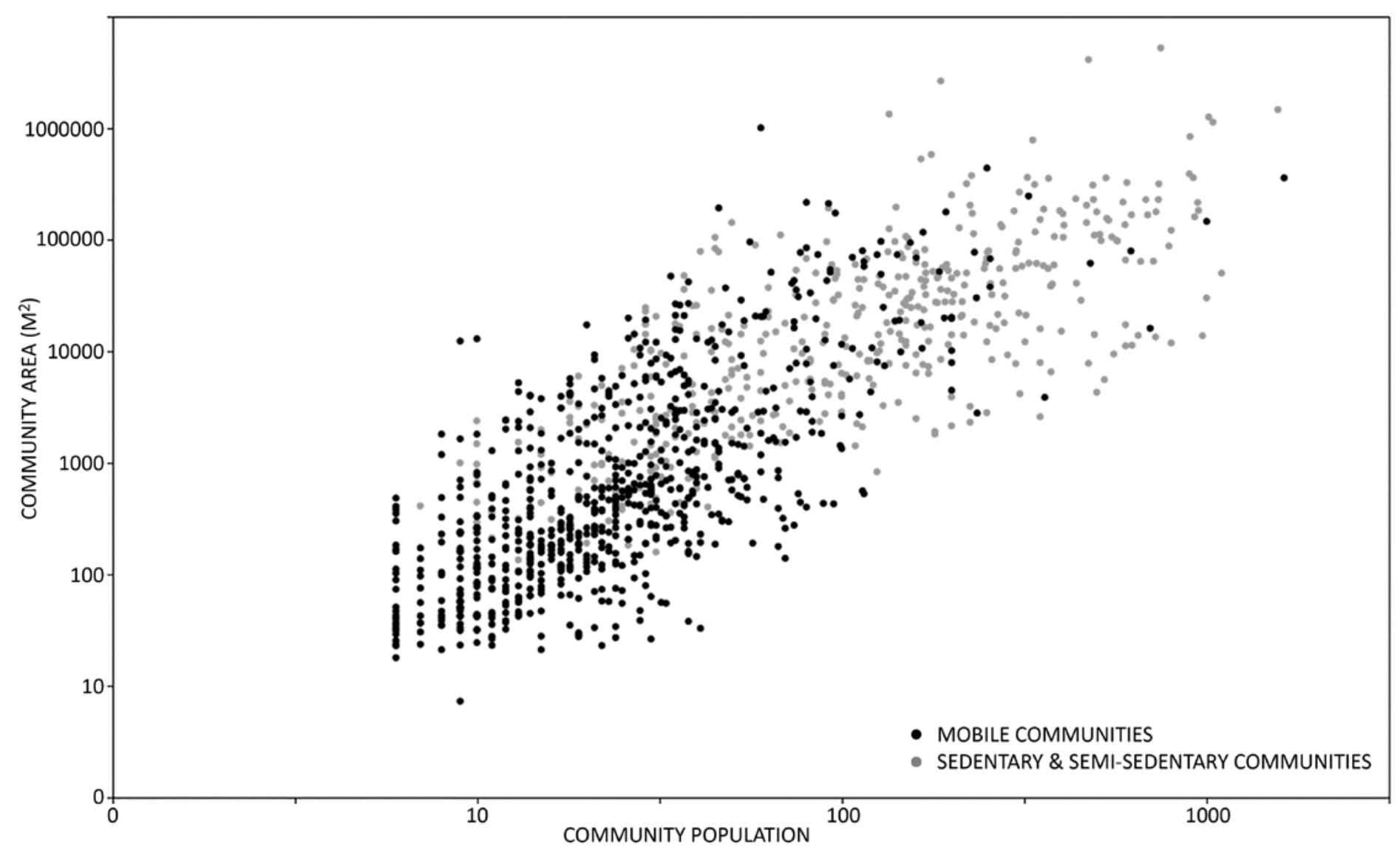

Figure 4. Relationship between population and occupation area for $H / G$ settlements included in the study. 